\title{
Overall Lifting Technology of Aluminum Plate Unit in the Air Corridor of Raffles City in Chongqing
}

\author{
Yajun Cao, Zhiyan Che*, Weixin Ma \\ China Construction Shenzhen Decoration Co., Ltd., Shenzhen, China
}

Email address:

7959025@qq.com (Zhiyan Che)

${ }^{*}$ Corresponding author

\section{To cite this article:}

Yajun Cao, Zhiyan Che, Weixin Ma. Overall Lifting Technology of Aluminum Plate Unit in the Air Corridor of Raffles City in Chongqing. Engineering and Applied Sciences. Vol. 4, No. 5, 2019, pp. 105-110. doi: 10.11648/j.eas.20190405.13

Received: August 2, 2019; Accepted: September 11, 2019; Published: September 25, 2019

\begin{abstract}
In this paper, we explore the installation method and process of large-span air corridor curtain wall of Chongqing Raffles Square Project. The curtain wall is positioned at the lower part of the sightseeing overpass, with the spans of $48.5 \mathrm{~m}$, $52.6 \mathrm{~m}$ and $54.1 \mathrm{~m}$ respectively, and the lengths of the cantilever sections are $25.1 \mathrm{~m}$ and $26.8 \mathrm{~m}$. At the junction of two rivers in Chongqing, several super high-rise buildings nearby exert strong aerodynamic interference effects. It is difficult to construct this project in a conventional way because intense airflow exists. Through an analysis of two construction options, with consideration to difficulties, quality, safety and economic costs of construction by the two options, the overall lifting of aluminum plate unit is chosen as the final plan. An introduction is made to practical operations of this option, including assembly of aluminum plate unit V-frame, tire frame installation, aluminum plate surface layer assembly, hydraulic synchronous lifting and unit body fixing. The hydraulic synchronous lifting process details the technical key points such as lifting point setting, lifting angle control, lifting and windproof measures, hydraulic lifting force control, hydraulic synchronous lifting control, etc. Finally, by utilizing this option, the quality, construction schedule, safety and cost for the overall lifting of units aloft can be guaranteed and good results are achieved in practice.
\end{abstract}

Keywords: Hydraulic Synchronization, Tire Frame, Lifting, Overall Unit

\section{Project Introduction}

Chongqing Raffles Square Project is located between Chongqing Chaotianmen Square and Jiefangbei, including 8 towers, namely T1, T2, T3S, T3N, T4S, T4N, T5 and T6, as well as the air corridor at the top of T2, T3S, T4S, T5 towers (see Figure 1). The sightseeing air corridor is about $193 \mathrm{~m}$ high from the ground, and the top elevation is about $220.9 \mathrm{~m}$. The basic unit comprises 83 round rings made of steel structure. It is elliptical with alternating peaks and valleys on the façade, which symbolize the "terrace and pit culture" unique to Chongqing. The curtain walls mainly consist of glass curtain wall, aluminum plate curtain wall and louver system etc. The aluminum plate curtain walls are located at the lower part of the sightseeing overpass, with the spans of $48.5 \mathrm{~m}, 52.6 \mathrm{~m}$ and $54.1 \mathrm{~m}$ respectively, and the lengths of the cantilever sections are $25.1 \mathrm{~m}$ and $26.8 \mathrm{~m}$. It is difficult to fix the aluminum plate surface layer and the main steel structure at the base by the V-shaped steel frame [1].

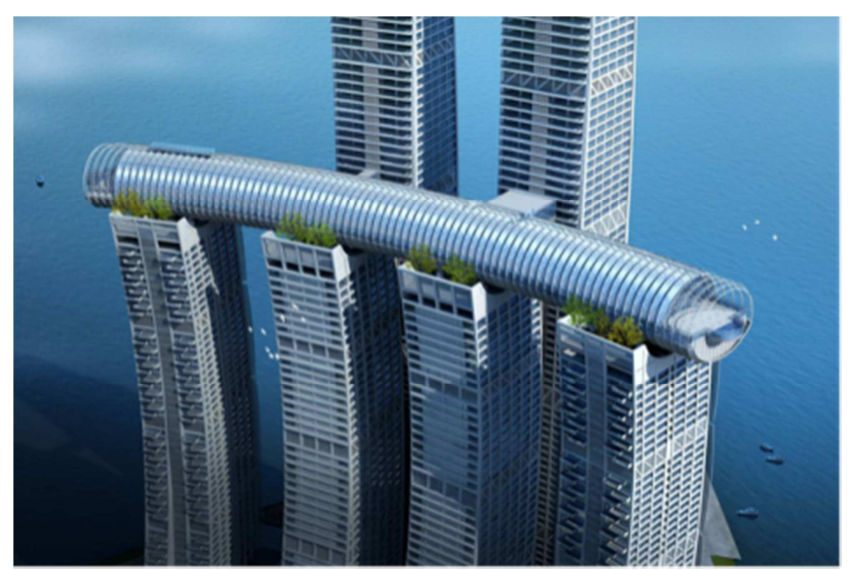

Figure 1. The architectural effect of the project.

\section{Determination of Installation Option}

1) Option 1: Staggering cantilever scaffold + cableway 
platform

The aluminum plate system on both sides at the lower arc of the corridor has a large radian [2]. If the staggering cantilever scaffold construction method is used, the unit elements must be installed from up to down. Since the scaffold erection affects the working face, it needs to install the aluminum plate while dismantling the scaffold (see Figure 2).

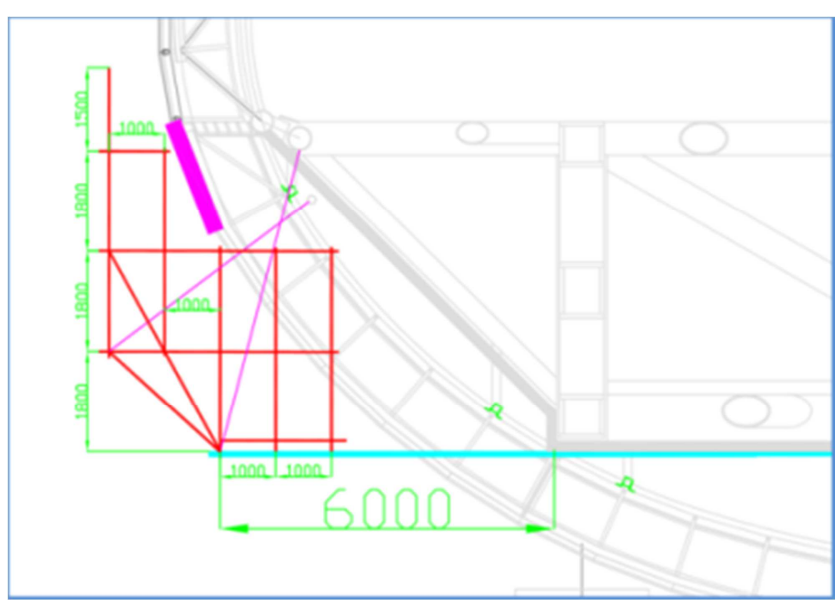

Figure 2. Schematic of staggering cantilever scaffold erection.

The aluminum plate system at the bottom of the lower arc has a small radian. A cableway platform is erected for construction [3]. There are towers on both sides, the steel wire rope is tied to the main structural mullion of the towers on both sides and fixed by buckles; if there are no towers on both sides, one section is fixed with a tower mullion and no tower position is pulled to the main steel beam made of steel structure. The 16\# steel wire rope is used as the main force support rope with a spacing of $5 \mathrm{~m}$. Every two ropes constitute a cableway portion with a spacing of $500 \mathrm{~mm}$ [4]. Adjacent cableways use hooks and may be joined together when necessary (see Figure 3).

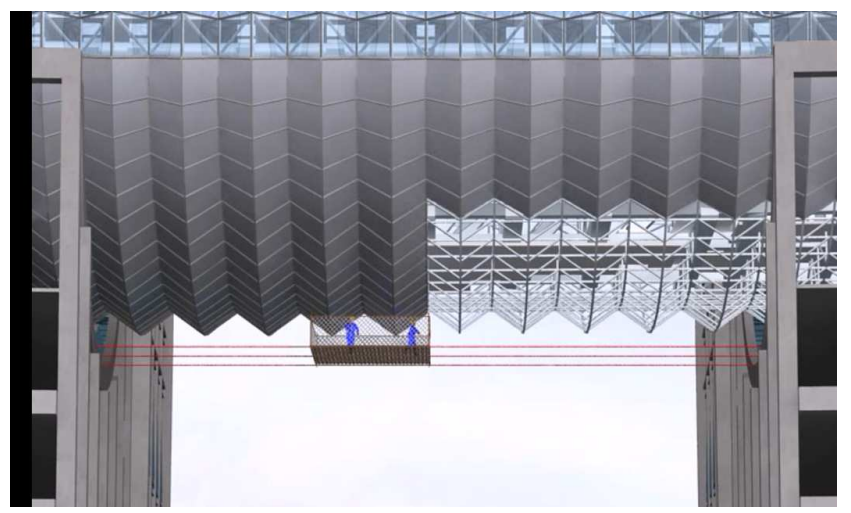

Figure 3. Schematic of cableway platform.

The characteristics of this option include guaranteed construction quality, difficulty in scaffold erection and dismantling, and reliable tie required between the cableway platform and the original structure. Both measures require a large amount of work at heights. All materials need to be transported vertically to the corridor before installation. There are too many unpredictable factors of construction safety, and construction from top to bottom is needed [5]. The construction period is long, about 120 days, and the estimated cost is 3 million RMB.

2) Option 2: Overall lifting of the aluminum plate unit

The complete semi-arc aluminum plates between towers are selected for lifting the entire piece, and the remaining portion is installed by erecting a scaffold platform on the tower. The keel and panel are assembled by erecting a tire frame on the ground, and then the overall lifting is realized by the hydraulic equipment fixed on the steel structure [6]. This option requires a small amount of work at heights, thus being safe and reliable. The assembly construction method may achieve high quality precision. The installation period is short, about 60 days. But the disadvantage is that there are high requirements for the lifting technology and the synchronous lifting should not cause deformation of the aluminum plate unit. The estimated cost of the option is 3.2 million RMB.

Taking comprehensive account of safety, schedule, quality and other factors of this project, the option of assembling in sections on the ground and locating at high altitude is more scientific and reasonable [7]. Therefore, Option 2 is selected.

\section{Overall Configuration}

Combined with the characteristics of the aluminum plate curtain wall arrangement, every four of 144 small units constitute one piece. A piece of structure mainly includes the V-shaped steel frame base and the aluminum plate surface layer of the curtain wall. The V-frame for the curtain wall steel structure is first assembled at the processing plant for measurement and check of overall dimension, then dismantled for hot-dip galvanizing, and finally reassembled for rechecking dimension. After recheck, it is disassembled into parts and transported to the site for assembly on the V-frame assembly platform. A tire frame is installed under the lifting as a support for the overall assembly and panel installation of the aluminum plate unit. Following the basic keel assembly of the V-frame assembly platform, the steel frame for overall lifting is assembled in tire frame [8]. Aluminum plates are transported to the site for installation using a transport frame. The panel is internally separable and hydraulic synchronous lifting is required after the panel is installed.

\section{Technical Difficulties and Countermeasures}

\subsection{V-shaped Steel Frame Assembly}

Every half ring of the V-frame for the curtain wall steel structure is divided into four small pieces, each of which is about $2.7 \mathrm{t}$ heavy and machined to be 9 parts in the factory. The square steel tube is machined and bent, the adapting piece is 
processed, and then the square steel tube is welded with the steel adapting piece into a whole. Each small piece of $\mathrm{V}$-frame for the curtain wall steel structure is assembled at the processing plant for measurement and check of overall dimension, then dismantled for hot-dip galvanizing, and finally reassembled for rechecking dimension [9]. After recheck, it is disassembled into parts and transported to the site for assembly on the V-frame assembly platform. The nine parts are assembled with bolts after they are transported to the site. The reinforced steel parts are welded at the site, and then the anti-corrosion treatment is carried out at the welding position. The V-frame is provided with a vertical steel square tube, which is arranged laterally along the structure. The steel square tube is used as a lower lifting point to lift the force rod. It is about $15 \mathrm{t}$ after the overall installation. The installation process is shown in Figure 4.
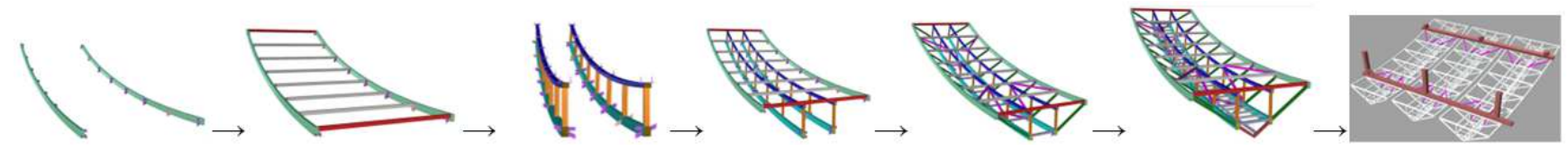

Figure 4. V-shaped steel frame assembly process.

\subsection{Installation of the Tire Frame}

The steel structure for the main structure of the podium is under the position of the tire frame and supported by the tire frame mullion. Because it is impossible to ensure that each point can be located in the position of the primary and secondary beams of the steel structure, in order to ensure safety, the tire frame mullion base is configured to be a frame of $1500 * 1500 \mathrm{~mm}$. During installation, the I-beam is used as the chassis of the tire frame for being welded and fixed to the main and secondary beams of the steel platform. After installation of the tire frame, the steel frame for locating (see Figure 5) is used to support the installation of the V-frame of the aluminum plate unit. In this process, the accuracy and dimension of the steel frame can be adjusted by the steel frame bracket of each small unit. The calculated counter force of the set position is submitted to a relevant entity for review [10]. In order to meet the installation schedule requirement, the tire frames are assembled, and all of them are machined into $3 \mathrm{~m}$-long finished truss in the processing plant, and then assembled directly (see Figure 6).

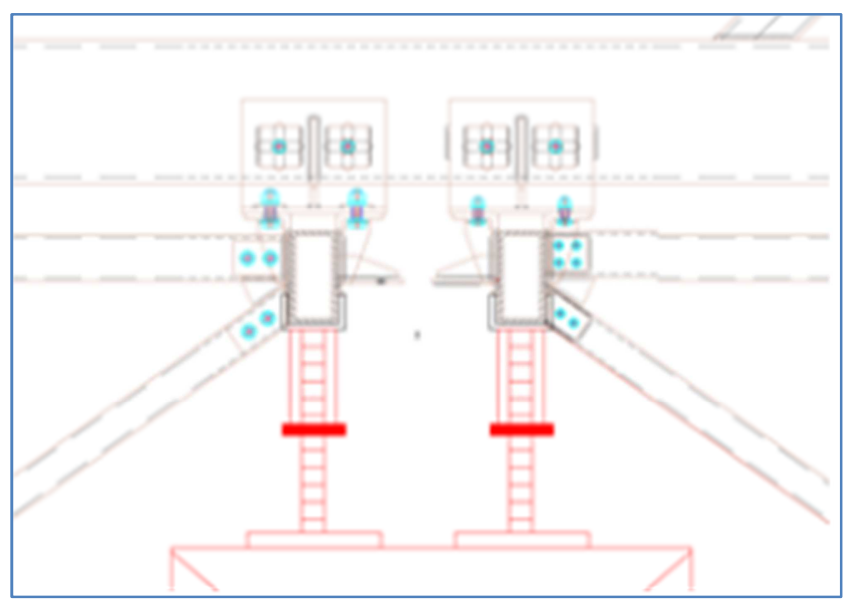

Figure 5. Steel frame bracket.

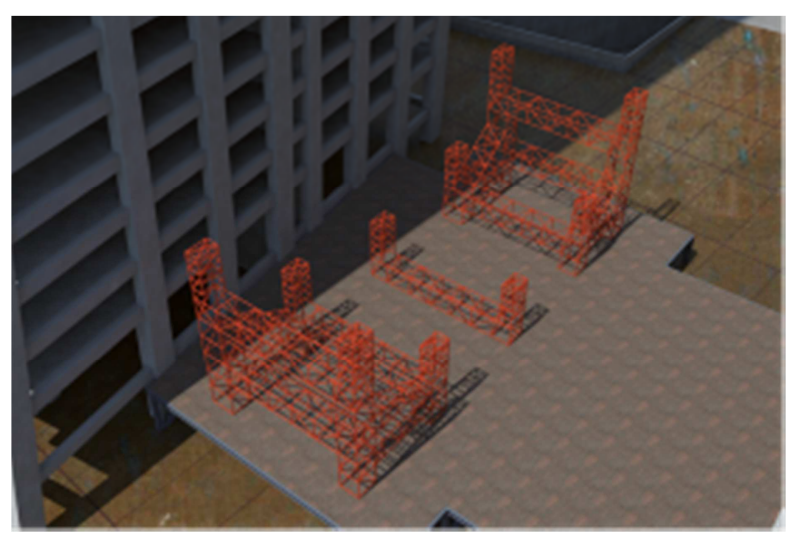

Figure 6. Tire frame assembly.

\subsection{Aluminum Panel Assembly}

The panels are assembled into spliced aluminum plate elements at the processing plant, which are transported by a transport frame to the site for installation. The panel is internally removable and easy for maintenance later. Panel installation needs to pay attention to the control of the plate clearance. Since the unitized curtain wall steel structure has 10 points supported on the tire frame bracket, and the panel cannot be installed at the bracket position, a clearance width must be accurately preserved [11]. The aluminum plate units are moved to the vertical position by the top synchronous lifting equipment and the horizontal pulling equipment.

\subsection{Hydraulic Synchronous Lifting}

(1) Configuration of lifting points

The V-shaped steel frame of the curtain wall is divided into four sections, and the connection between each section is weak. Considering the structural stress and the difficulty in lifting control, the principle is not changing the structural stress system so that the stress ratio and deformation of the structure during the lifting process can be controlled within an acceptable range.

Lift up the upper lifting point, namely the lifting platform, on which hydraulic lifter is configured. The hydraulic lifter is connected to the corresponding lower lifting point on the overall lifting unit of the steel structure by the special lifting steel strand. The upper lifting point is arranged on the lifting 
steel beam, which is welded to the embedded part on the top floor of the main structural steel beam through the short column, and configured with a lateral support that is connected to the main structure floor at one end to ensure the stability out of the lifting steel beam surface. The lifting ceiling arrangement is shown in Figure 7.

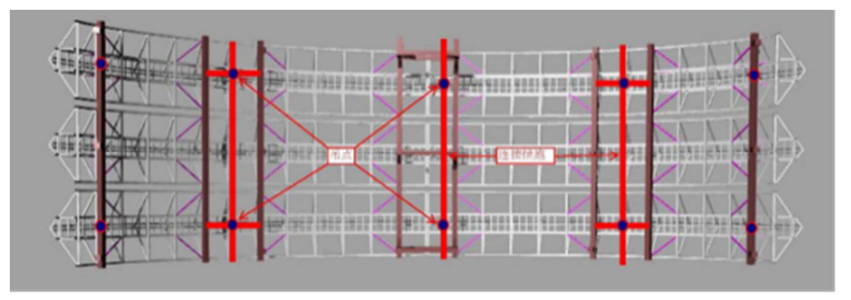

Figure 7. Lifting points of V-shaped steel frame.

(2) Control of lifting angle

Due to the particularity of the steel platform, locating of the tire frame somewhat deviates from the actual lifting position. Also, the tire frame itself cannot move, so there may be tilting during installation. For example, 12 ring aluminum plate units exist between T3S and T4S. Except for the two rings on both sides of the towers are installed by the slip method, there are two 3-piece and one 2-piece aluminum plate curtain walls. By comparison and analysis, the lifting angles of the two 3-piece plates are $1^{\circ}$ and $2^{\circ}$ respectively, and the maximum angle is $6^{\circ}$; and the maximum change of the position of each lifting point is $861 \mathrm{~mm}$ [12]. In order to ensure that the plates can be lifted vertically, at the beginning of the lifting, a reverse pulling force is applied in the opposite direction of the tilt (see Figure 8 ) so that the plates slowly return to the vertical state.

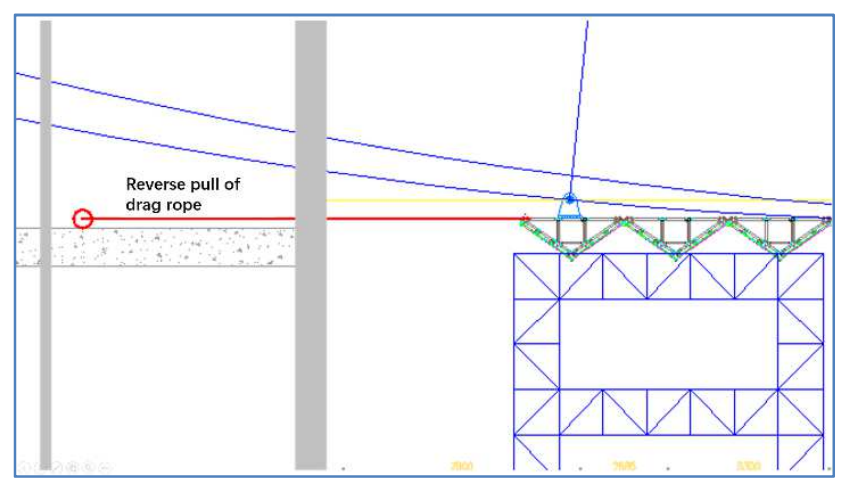

Figure 8. Reverse pull of drag rope.

(3) Windproof measures for lifting

The project is located at the Chaotianmen where the Yangtze River and the Jialing River meet, with the Yangtze River in the east and the Jialing River in the west. The wind force is large. The entire lifting unit is lightweight with a large wind area, thus being prone to sway. In order to minimize the influence of wind on the lifting process of the aluminum plate unit, a vertical structural hawser wire rope (and pre-stress is applied) is placed on each side of the structure (see Figure 9). As the vertical slideway of the hawser wire rope during lifting, horizontal support points of the vertical steel wire ropes are configured on the reserved floors of towers to reduce the span of the hawser wire rope, increase its rigidity, and decrease the horizontal movement of the structure.

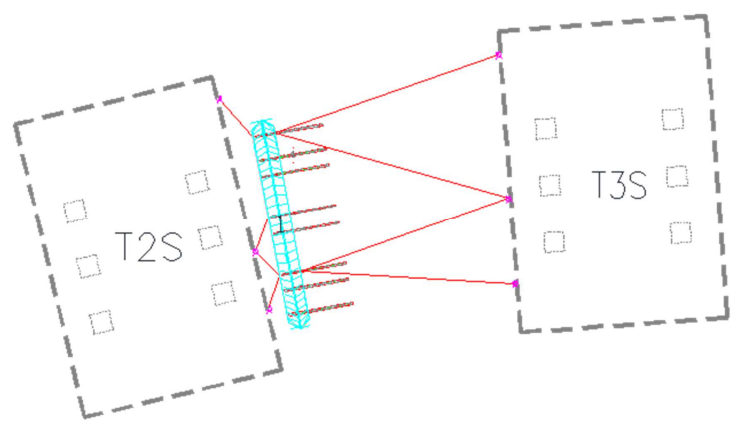

Figure 9. Hawser wire rope.

During lifting construction, the project department should pay close attention to the local weather conditions and install a wind speed observer at the current lifting position. In the lifting process, when there is a strong wind of scale 5 or above, the operation is stopped immediately, and the titled wire rope is temporarily fixed on the nearest reserved floor.

The lifting weight of the project is small. After the installation of curtain wall panels, the structure is subjected to a large load area. In order to ensure the structural safety during lifting, effective windproof measures must be taken in the entire lifting construction process [13].

(4) Hydraulic lifting force control

10 sets of $75 t$ hydraulic synchronous lifting equipment are used for lifting. Unlike common winch or crane lifting, the hydraulic lifting equipment can control the starting acceleration and braking acceleration by adjusting the system pressure and flow, so as to ensure the stability of arc-shaped aluminum plate units and main tower structure during lifting. In the lifting process, the cableway windproof tie is used for wind protection.

Before lifting, the computer simulation analysis is made to the arc-shaped aluminum plate units for overall lifting. Considering the influence of non-uniform load distribution, asynchrony of lifting, construction load, wind load, dynamic load and other factors, the lifting counterforce of each lifting point under the overall synchronous lifting condition of arc-shaped aluminum plate unit is calculated. The asynchronous error of each lifting point is controlled at $20 \mathrm{~mm}$, and then by analyzing the worst working conditions of single-point asynchrony, two-point asynchrony and three-point asynchrony, the maximum lifting point counterforce within the safety range is obtained. In the hydraulic synchronous lifting system, the maximum lifting force of each hydraulic lifter is set according to calculation data. When the actual lifting force of a lifting point shows a trend of exceeding the set value, the hydraulic lifting system automatically adopts overflow unloading so that the lifting point counterforce is controlled within the set value to prevent the seriously non-uniform distribution of lifting counterforce at each lifting point. 
Table 1. Computer simulation analysis of arc-shaped aluminum plate unit.

\begin{tabular}{lllll}
\hline & Synchronous lifting & Single-point asynchrony & Two-point asynchrony & Three-point asynchrony \\
\hline Asynchronous error of ceiling & 0 & 20 & 20 & 20 \\
Max. stress ratio of unit body/\% & 0.59 & 0.589 & 0.688 & 0.60 \\
Pull of steel strand /KN & 69 & 73 & 86 & 69 \\
\hline
\end{tabular}

(5) Hydraulic synchronous lifting control

After initial lifting and leaving $500 \mathrm{~mm}$ from the tire frame, apply the static load for 1 hour. When the static load test is passed, the panel is installed at the bracket. Then continue to lift. The lifting speed is between $10 \mathrm{~m} / \mathrm{h}$ and $15 \mathrm{~m} / \mathrm{h}$. A total station is used to monitor and measure the control accuracy and the lifting error. The hydraulic system adjustment error is controlled according to the synchronization error. To prevent the error accumulation, the error is adjusted for every 40 to 50 strokes. Continue to lift for 2 days. The lifting speed is reduced to $5 \mathrm{~m} / \mathrm{h}$ at a distance of about $2 \mathrm{~m}$ from the installation position, and finally the locating, lifting and installation are completed.

In the lifting process, structural members need to be pulled by the hawser wire rope to prevent them from turning at high altitude and causing safety hazard and facilitate them to be in place [14].

\subsection{Locating and Fixation of Unit Body}

The main structure will inevitably be welded after the overall lifting of arc-shaped aluminum plate units and in the subsequent construction. Furthermore, according to the adjustment needs of building function, there may be circumstances under which the local load deviates from the design working condition.

Given the characteristics of a large span of the arc-shaped aluminum plate units without rigid support in the middle, after installation and locating, welding in a wide range and with a large current is prohibited, so as to prevent local heating and softening. After arc-shaped units are connected, the steel ties connecting the lifting points will be removed. An entire arc-shaped unit is split into four small aluminum plate units to avoid uncontrollable deflection and abrupt change of the structural space size [15]. Therefore, before the overall installation and construction of the arc-shaped aluminum plate units, all possible embedded parts, lifting points and E-shaped connecting pieces should be considered as far as possible, and the installation and welding may be finished in advance on the ground.

\section{Conclusions}

With a case study of the air corridor curtain wall of Chongqing Raffles Square Project, this paper investigates the installation of aluminum curtain wall aloft with large spans. A hydraulic synchronous technique is proposed and realized for the first time in the world for the overall lifting of aluminum plate units of super high-rise buildings. This technique comprises assembly of V-shaped steel frame, installation of tire frame, assembly of aluminum panel, setting of hydraulic lifting points, control of lifting angle, windproof measures for lifting, control of hydraulic lifting force, control of hydraulic synchronous lifting and locating and fixation of unit body. It provides a new idea for similar projects. The project construction is smooth on the worksite because the lifting technique is safe and reliable, thus guaranteeing the construction quality and schedule and allowing the construction cost controllable. It is of great significance as reference for the curtain wall construction at the cantilever sections of high-rise or super high-rise buildings in a complicated environment.

\section{References}

[1] Wang Xianzhang, Li Tieliang and Du Xiaohong. Installation of Large-span Hyperboloid Steel Arch Truss for People's Daily Project [J]. Construction Technology, 2014 (6): 33-35.

[2] Zhu Jiang and Yu wentao. Construction Technology of Large-span Heavy Steel Truss Within the Narrow Space [J]. Construction Technology, 2015, (22): 54-57.

[3] Yang Zhimeng, Zhou Wenwu, Huang Haijun and Xie Hong. Integral Hoisting Technique of Polyhedron Unit Plate Curtain Wall [J]. Theoretical Research in Urban Construction, 2013, (17): 1.

[4] Zhou Xujing, Shen Jie and Du Jiqiang. Circular Track Hoisting Technology of Unit Curtain Wall [J]. Architectural Engineering Technology and Design, 2016 (24): 2.

[5] Ministry of Housing and Urban-Rural Development of the People's Republic of China. GB 51162-2016 Technical code for integral lifting of heavy structure and equipment [S]. Beijing: Standards Press of China, 2016.

[6] Ministry of Housing and Urban-Rural Development of the People's Republic of China. GB50300-2013 Unified standard for constructional quality acceptance of building engineering [S]. Beijing: Standards Press of China, 2013.

[7] Ministry of Housing and Urban-Rural Development of the People's Republic of China. JGJ80-2016 Technical code for safety of working at height of building construction [S]. Beijing: Standards Press of China, 2016.

[8] Ministry of Housing and Urban-Rural Development of the People's Republic of China. JGJ59-2011 Standard for construction safety inspection [S]. Beijing: Standards Press of China, 2011.

[9] Ministry of Construction of the People's Republic of China. JGJ 131-2001 Technical code for metal and stone curtain walls [S]. Beijing: Standards Press of China, 2001.

[10] Wang Dong and Zhang Rui. Construction Technology for Installation of Fabricated Curtain Wall Units Located at Construction Elevator [J]. Building Construction, 2016, 38 (11): $1549-1550$. 
[11] Ministry of Housing and Urban-Rural Development of the People's Republic of China. GB 50009-2012 Load code for the design of building structures [S]. Beijing: Standards Press of China, 2012.

[12] Huang Zibin and Mao Kefeng. Analysis of Construction Technology for Installation of Unit Curtain Wall [J]. Construction Technology, 2014, (8): 1.

[13] Hu Zhihong. Construction Method of Framing Curtain Wall by Hoisting [J]. Construction Technology, 2017, (8): 92-93.
[14] Ministry of Housing and Urban-Rural Development of the People's Republic of China. GB50017-2017 Code for design of steel structure [S]. Beijing: Standards Press of China, 2017.

[15] Jiang Na and Ma Tuo. Lifting Technology of Unit Curtain Walls for Super High-rise Tower Buildings [J]. Construction Science and Technology, 2017, (13): 94-95. 